\title{
Chewing performance in orthodontic patients treated with extraction of premolars
}

\author{
Insan Jang*, Eunhye Jang, Dong-Soon Choi, Bong-Kuen Cha \\ Department of Orthodontics, College of Dentistry, Gangneung-Wonju National University, Gangneung, Korea
}

\begin{abstract}
The purpose of the present study was to evaluate the kinematic parameters of the chewing cycles in patients who had undergone comprehensive orthodontic treatment with extraction of premolars and to compare these parameters with those of a non-extraction group. The samples for this retrospective study consisted of kinesiographic recordings obtained from patients who had undergone comprehensive orthodontic treatment without orthognathic surgery. They were divided into a non-extraction group ( $\mathrm{n}=19)$ and an extraction group $(n=40)$ depending on whether their premolars were extracted for orthodontic treatment. Mandibular kinesiography was recorded using Bio-EGN before (T1) and after (T2) the treatment, and chewing cycle time, velocity, the position of turning point, and the lateral width of the cycle were measured. No significant difference was found in most of the kinematic parameters between the extraction and non-extraction groups at T1 and in those between $\mathrm{T} 1$ and $\mathrm{T} 2$ in the non-extraction group. In the extraction group, on the other hand, opening and closing velocities significantly decreased and the turning point of the chewing cycle was significantly more superior at T2 than at T1. The chewing cycle time did not significantly differ between T1 and T2 in the extraction group. Patients who have undergone orthodontic treatment with premolar extraction have chewing cycles that are shorter and slower than those before the treatment, and their chewing movement may differ from that of those who have not undergone extraction.
\end{abstract}

Key Words: Chewing, Malocclusion, Mastication, Premolar, Tooth extraction

@C This is an open-access article distributed under the terms of the Creative Commons Attribution Non-Commercial License (http://creativecommons.org/licenses/by-nc/4.0) which permits unrestricted noncommercial use, distribution, and reproduction in any medium, provided the original work is properly cited.

\section{INTRODUCTION}

Masticatory function had been evaluated usually by the particle size of food after a standardized number of chewing cycles [1], the number of chewing cycles required to reduce foods to a certain size [2], maximum bite force, mixing ability [3], mandibular movement in chewing, chewing pattern [4,5], or occlusal contact area [3,6]. Malocclusion has been reported to be associated with reduced masticatory functions [1-3]. In cross bite or open bite patients, maximum bite force, occlusal contact area, mixing ability were lower than normal group [6]. Median particle sizes in patients undergoing orthognathic surgery were larger than control group [7].

In the kinesiographic studies, the paths of motion of central incisors was measured and chewing time, velocity, and chewing pattern of patients with malocclusion were analyzed [8-10]. Several studies reported chewing cycles in

Received May 22, 2019; Revised July 9, 2019; Accepted July 11, 2019

Corresponding author: Insan Jang, Department of Orthodontics, College of Dentistry, Gangneung-Wonju National University, 7 Jukheon-gil, Gangneung 25457, Korea.

Tel: +82-33-640-2762, Fax: +82-33-640-3057, E-mail: insan@gwnu.ac.kr

Copyright $\odot$ 2019, Oral Biology Research Institute 
patients with crossbite, or prognathic malocclusion were different with those of normal groups [10,11]. Children with anterior open bite showed a shorter closing duration and a reduced width of the chewing cycle than normal occlusion group [9]. On the other hands, no significant differences were found in chewing patterns among patients with Angle Class I and Class II malocclusion [12].

Extraction of premolars are performed to gain spaces for tooth alignment in crowded teeth or to achieve an esthetic soft tissue profile following retraction of anterior teeth. Many studies have investigated changes in the skeletal and soft tissue parameters in orthodontic patients treated with premolar extractions [13,14]. However, there were only a few reports that evaluated changes in masticatory function in orthodontic patients treated with premolar extraction [14-17]. Tome et al. [16] concluded in their kinesiology study that skillfulness in mandibular movement did not differ between extraction and non-extraction groups. Yoon et al. [17] reported that the area of tooth contact and occlusal force reduced after orthodontic treatment with extraction of premolars.

To our knowledge, no previous study evaluated changes in chewing kinematic parameters of mandibles in orthodontic patients treated with premolar extraction. It is still uncertain whether chewing movement learned under the influence of malocclusion is altered by correcting dental relationships or does not change after treatment. Therefore, the purpose of the present study was to evaluate the kinematic parameters of the chewing cycles in patients who had undergone comprehensive orthodontic treatment with extraction of premolars, and to compare those with non-extraction group.

\section{MATERIALS AND METHODS}

The samples for this retrospective study were collected from the kinesiographic recordings obtained from orthodontic patients who had been treated in the Department of Orthodontics, Gangneung-Wonju National University Dental Hospital. Samples were recruited consecutively with the following inclusion criteria: (1) they had undergone comprehensive orthodontic treatment with fixed orthodontic appliances, (2) the kinesiographic recordings and lateral cephalograms were available which were taken before (T1) and after orthodontic treatment (T2), (3) older than 18 years of age at T1, (4) no orthognathic surgery, (5) no missing molars. They were divided into extraction groups that more than two premolars were extracted for orthodontic treatment and non-extraction groups. All the patients were treated by one investigator. This study was reviewed and approved by the Institutional Review Board at the Gangneung-Wonju National University Dental Hospital (IRB no. 2017-007).

\section{Kinesiographic recordings}

The chewing movement of the mandible was recorded using the Bio-EGN (BioReasearch Inc., Milwaukee, WI, USA). The recording magnet was fixed to the labial surfaces of the lower central incisors. The subjects were seated

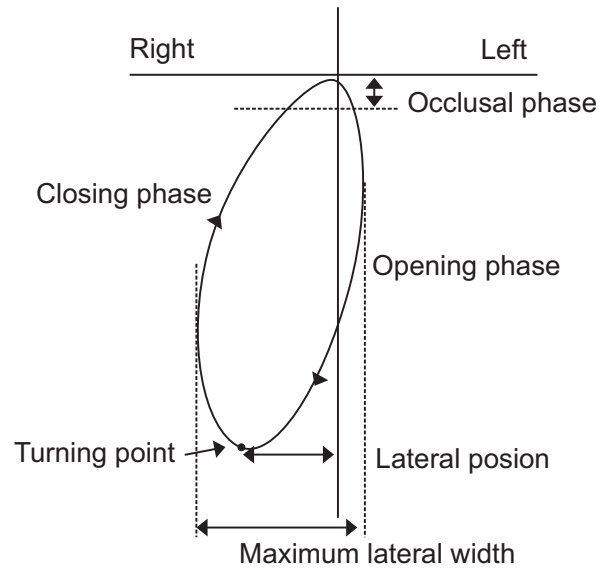

Maximum lateral width

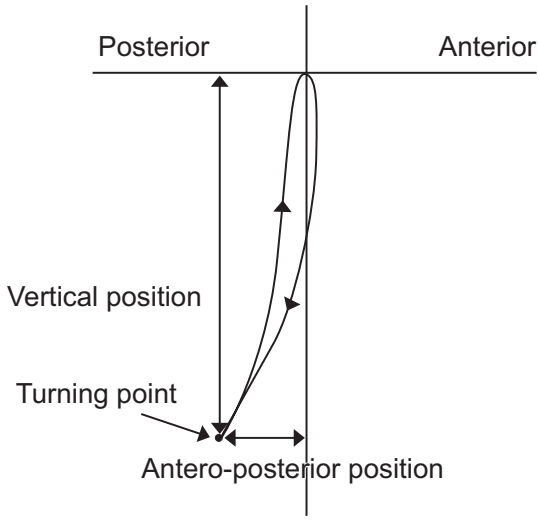

Fig. 1. Kinematic parameters used in this study. 


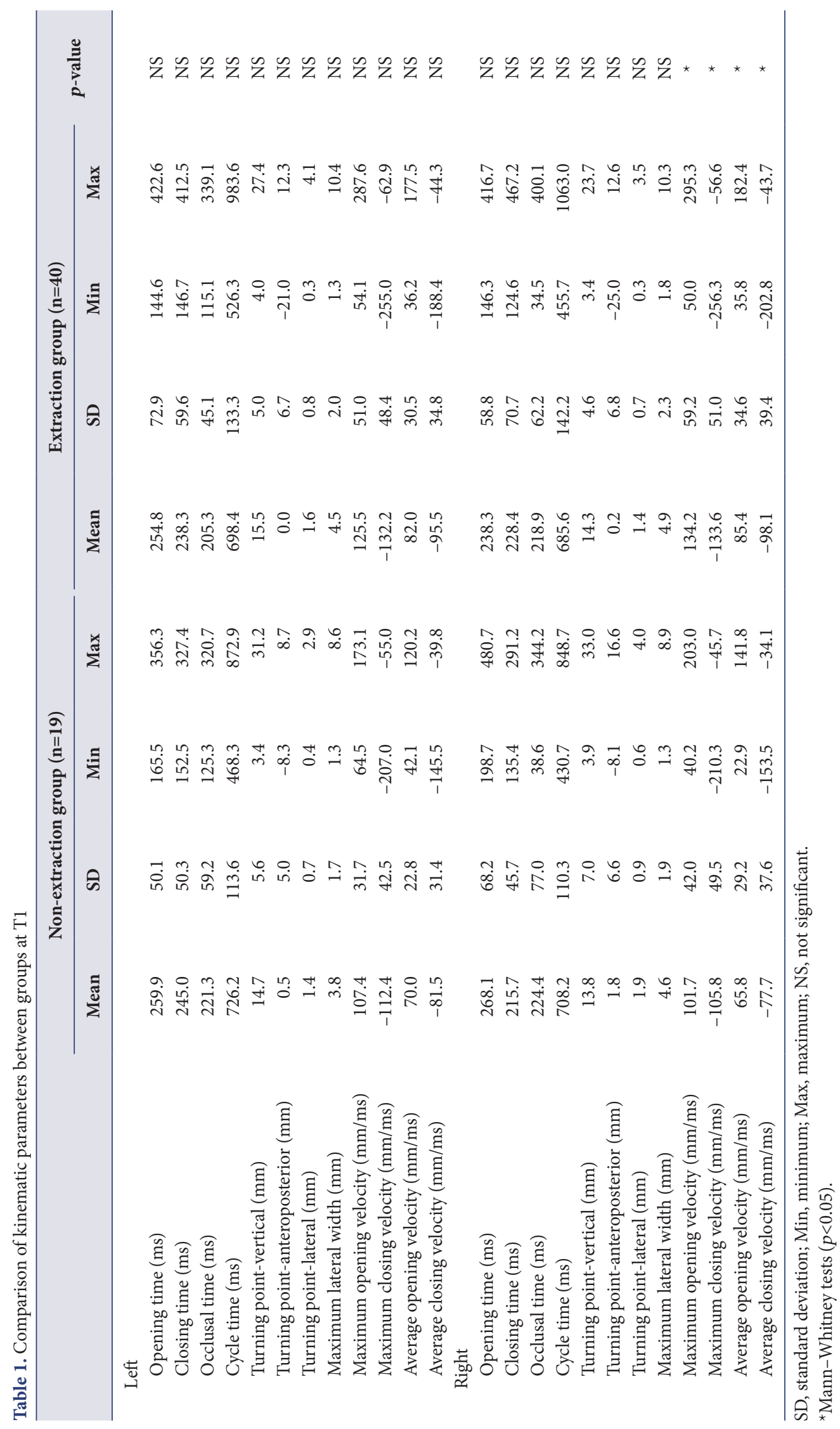


upright without restriction of the head, and the tracking sensor was placed on the head. The position of the magnet was zeroed at the origin when the teeth were in maximum intercuspation position. Subjects were instructed to chew and fully soften half a piece of chewing gum (XYLITOL; Lotte Confectionery Co., Seoul, Korea) before the recording. Left- and right-sided chewing movements were recorded for 20 seconds, respectively at T1 and at T2. Recording at $\mathrm{T} 2$ were taken between 3 and 12 months of retention period. Cycle time in the opening, closing, occlusal phases, velocity, vertical, anteroposterior, and lateral position of turning point of chewing cycle, maximum lateral width were calculated (Fig. 1).

\section{Statistical analysis}

As the chewing parameters did not show the normal distribution, nonparametric analysis was used to test the changes in chewing parameters. The kinematic parameters were compared between the left side and the right side using the Wilcoxon signed-rank test. Since there were statistical differences in between the sides, values from each side were evaluated separately. Wilcoxon signed-rank test was used to compare the parameters at T1 and T2. $p<0.05$ was taken to indicate statistical significance. All statistical analyses were performed using PASW ver. 18.0 (IBM Corp., Armonk, NY, USA).

Table 2. Differences in kinematic parameters (T2-T1)

\begin{tabular}{|c|c|c|c|c|c|c|c|}
\hline \multirow{2}{*}{$\Delta(\mathrm{T} 2-\mathrm{T} 1)$} & \multicolumn{3}{|c|}{ Non-extraction group $(n=19)$} & \multicolumn{3}{|c|}{ Extraction group $(n=40)$} & \multirow{2}{*}{$\begin{array}{c}\begin{array}{c}\text { Non-extraction } \\
\text { vs. extraction }\end{array} \\
p \text {-value }\end{array}$} \\
\hline & Mean & SD & $p$-value & Mean & SD & $p$-value & \\
\hline \multicolumn{8}{|l|}{ Left } \\
\hline$\Delta$ Opening time & 3.3 & 73.8 & & -0.7 & 97.1 & & \\
\hline$\Delta$ Closing time & 0.0 & 98.1 & & -6.7 & 110.0 & & \\
\hline$\Delta$ Occlusal time & -10.4 & 71.3 & & 19.5 & 67.1 & & \\
\hline$\Delta$ Cycle time & -7.2 & 175.1 & & 12.1 & 240.2 & & \\
\hline$\Delta$ Turning point-vertical & 0.1 & 5.6 & & -2.2 & 6.1 & * & \\
\hline$\Delta$ Turning point-anteroposterior & 0.2 & 6.9 & & -0.3 & 8.5 & & \\
\hline$\Delta$ Turning point-lateral & 0.2 & 0.6 & & -0.3 & 0.8 & * & \\
\hline$\Delta$ Maximum lateral width & 1.3 & 1.4 & * & -0.4 & 2.2 & & $\dagger$ \\
\hline$\Delta$ Maximum opening velocity & -4.6 & 28.7 & & -19.3 & 49.3 & * & \\
\hline$\Delta$ Maximum closing velocity & -3.6 & 41.6 & & 16.7 & 48.3 & * & \\
\hline$\Delta$ Average opening velocity & 0.6 & 20.1 & & -11.0 & 29.8 & * & \\
\hline$\Delta$ Average closing velocity & -3.1 & 32.1 & & 10.9 & 36.1 & & \\
\hline \multicolumn{8}{|l|}{ Right } \\
\hline$\Delta$ Opening time & -15.6 & 97.0 & & 6.7 & 89.7 & & \\
\hline$\Delta$ Closing time & -6.7 & 63.9 & & -12.5 & 108.1 & & \\
\hline$\Delta$ Occlusal time & -3.0 & 73.6 & & 16.0 & 91.6 & & \\
\hline$\Delta$ Cycle time & -25.4 & 137.2 & & 10.2 & 225.1 & & \\
\hline$\Delta$ Turning point-vertical & -0.2 & 5.9 & & -1.8 & 5.9 & * & \\
\hline$\Delta$ Turning point-anteroposterior & -0.9 & 8.2 & & -0.3 & 8.7 & & \\
\hline$\Delta$ Turning point-lateral & -0.4 & 1.0 & & -0.1 & 0.8 & & \\
\hline$\Delta$ Maximum lateral width & 0.3 & 2.2 & & -0.3 & 2.7 & & \\
\hline$\Delta$ Maximum opening velocity & -1.1 & 41.1 & & -24.5 & 55.3 & * & $\dagger$ \\
\hline$\Delta$ Maximum closing velocity & -10.6 & 51.1 & & 20.5 & 46.4 & * & $\dagger$ \\
\hline$\Delta$ Average opening velocity & 2.4 & 25.8 & & -13.2 & 32.9 & * & \\
\hline$\Delta$ Average closing velocity & -9.5 & 38.8 & & 13.7 & 35.8 & * & $\dagger$ \\
\hline
\end{tabular}

${ }^{*}$ Wilcoxon signed rank test was applied for estimating the differences between T1 and T2. ${ }^{\dagger}$ Mann-Whitney test was used for comparing the differences between non-extraction and extraction groups $(p<0.05)$.

SD, standard deviation. 


\section{RESULTS}

The comparison of kinesiographic parameters between groups at $\mathrm{T} 1$ are presented in Table 1 . No significant difference was found in most of the kinematic parameters between extraction and non-extraction groups before treatment. As shown in Table 2, on the other hands, opening and closing velocities significantly decreased, and turning point of chewing cycle displaced more superior at $\mathrm{T} 2$ in extraction group. Cycle time did not significantly differ between T1 and T2 either in extraction group nor in nonextraction group.

\section{DISCUSSION}

We reviewed chewing kinematic records obtained form 59 patients before and after orthodontic treatment retrospectively. Our results indicate that chewing cycle time does not change for almost 2 years of orthodontic treatment both extraction and non-extraction groups. However, mandibular chewing cycle became short and narrow after orthodontic treatment in extraction group, with significant decreasing in chewing velocity. Interestingly nonextraction group did not show evident change in chewing kinematics after treatment.

Chewing cycle time might be less influenced by malocclusion. Earlier studies also reported that no significant difference were found in chewing cycle time between deep bite and control groups [8], and between crossbite and normal groups [11]. In regard to the location of turning point, we expected that those parameters increase after treatment, because mandibular movement might be less impeded after eliminating unfavorable occlusal interference by tooth alignment. However, the position of turning point did not significantly change in non-extraction group and chewing cycle in extraction group became short in vertical direction and chewing width tend to be narrow after treatment. This might be associated with decreased dental arch width after extraction treatment [18], and other contributing factors in mastication such as occlusal curvature [19], occlusal guidance angle [20].

It still remains unclear whether slim and drop shaped chewing cycles means impaired masticatory function or it represents effective and reproducible movement for chewing. Uesugi and Shiga [21] evaluated masticatory function by measuring the amount of glucose extraction using a gummy jelly in normal male group. They concluded that masticatory performance improves as the opening distance and chewing velocity increase. They also found that the amount of glucose extraction increased as chewing width increased up to a $3 \mathrm{~mm}$, and tended to decrease with more than $4 \mathrm{~mm}$ of width [21]. In our study, the mean of the maximum chewing width was greater than $3 \mathrm{~mm}$ in both groups and showed a tendency to decrease in extraction group, and increase in non-extraction group.

We did not included subjects who required surgical procedure for treatment in the present study. Bourdiol et al. [22] previously reported in their chewing study using carrots that subjects with severe skeletal discrepancy had definitely impaired mastication, but mild malocclusion group who treated by orthodontic treatment alone compensates their deficient occlusion during mastication. Mandibular movement for chewing is closely related with the hardness of chewing food. The vertical movement increases for soft food, the lateral movement for hard food, and cycle time prolongs progressively with increasing the hardness of food [4,23]. Therefore, in the present study, kinesiographic recording was not started until patients had completely soften the chewing gum for standardization of test food. In conclusion, patients undergone orthodontic treatment with premolar extraction have chewing cycles shorter and less speedy than before treatment, and their chewing movement may differ with those of non-extraction.

\section{ACKNOWLEDGEMENTS}

This study was financially supported by the Scientific Research grant (SR1702) of Gangneung-Wonju National University Dental Hospital.

\section{CONFLICTS OF INTEREST}

The authors declare that they have no competing interests. 


\section{ORCID}

\author{
Insan Jang \\ https://orcid.org/0000-0001-7946-9212 \\ Eunhye Jang \\ https://orcid.org/0000-0002-3213-9942 \\ Dong-Soon Choi \\ https://orcid.org/0000-0002-2892-2002 \\ Bong-Kuen Cha \\ https://orcid.org/0000-0001-5699-9421
}

\section{REFERENCES}

1. English JD, Buschang PH, Throckmorton GS. Does malocclusion affect masticatory performance? Angle Orthod 2002;72:21-27. doi: 10.1043/0003-3219(2002)072<0021: DMAMP $>2.0 . \mathrm{CO} ; 2$.

2. Magalhães IB, Pereira LJ, Marques LS, Gameiro GH. The influence of malocclusion on masticatory performance. A systematic review. Angle Orthod 2010;80:981-987. doi: 10.2319/011910-33.1.

3. Bae J, Son WS, Kim SS, Park SB, Kim YI. Comparison of masticatory efficiency according to Angle's classification of malocclusion. Korean J Orthod 2017;47:151-157. doi: 10.4041/kjod.2017.47.3.151.

4. Yamashita S, Hatch JP, Rugh JD. Does chewing performance depend upon a specific masticatory pattern? J Oral Rehabil 1999;26:547-553. doi: 10.1046/j.13652842.1999.00446.x.

5. Nie Q, Kanno Z, Xu T, Lin J, Soma K. Clinical study of frontal chewing patterns in various crossbite malocclusions. Am J Orthod Dentofacial Orthop 2010;138:323-329. doi: 10.1016/j.ajodo.2008.10.020.

6. Choi TH, Kim BI, Chung CJ, Kim HJ, Baik HS, Park YC, Lee KJ. Assessment of masticatory function in patients with non-sagittal occlusal discrepancies. J Oral Rehabil 2015;42:2-9. doi: 10.1111/joor.12227.

7. Zarrinkelk HM, Throckmorton GS, Ellis E 3rd, Sinn DP. A longitudinal study of changes in masticatory performance of patients undergoing orthognathic surgery. J Oral Maxillofac Surg 1995;53:777-782; discussion 782-783. doi: 10.1016/0278-2391(95)90331-3.

8. Buschang PH, Throckmorton GS, Austin D, Wintergerst AM. Chewing cycle kinematics of subjects with deepbite malocclusion. Am J Orthod Dentofacial Orthop 2007;131:627-634. doi: 10.1016/j.ajodo.2005.06.037.

9. Piancino MG, Isola G, Merlo A, Dalessandri D, Debernardi C, Bracco P. Chewing pattern and muscular activation in open bite patients. J Electromyogr Kinesiol 2012;22:273279. doi: 10.1016/j.jelekin.2011.12.003.

10. Kubota T, Yagi T, Tomonari H, Ikemori T, Miyawaki S.
Influence of surgical orthodontic treatment on masticatory function in skeletal Class III patients. J Oral Rehabil 2015;42:733-741. doi: 10.1111/joor.12307.

11. Tomonari H, Ikemori T, Kubota T, Uehara S, Miyawaki S. First molar cross-bite is more closely associated with a reverse chewing cycle than anterior or pre-molar cross-bite during mastication. J Oral Rehabil Dec 2014;41:890-896. doi: 10.1111/joor.12222.

12. Proeschel PA. Chewing patterns in subjects with normal occlusion and with malocclusions. Semin Orthod 2006;12:138-149. doi: 10.1053/j.sodo.2006.01.007.

13. Meral O, Işcan HN, Okay C, Gürsoy Y. Effects of bilateral upper first premolar extraction on the mandible. Eur J Orthod 2004;26:223-231. doi: 10.1093/ejo/26.2.223.

14. Alexander TA, Gibbs CH, Thompson WJ. Investigation of chewing patterns in deep-bite malocclusions before and after orthodontic treatment. Am J Orthod 1984;85:21-27. doi: 10.1016/0002-9416(84)90119-2.

15. Heiser W, Stainer M, Reichegger H, Niederwanger A, Kulmer S. Axiographic findings in patients undergoing orthodontic treatment with and without premolar extractions. Eur J Orthod 2004;26:427-433. doi: 10.1093/ejo/26.4.427.

16. Tome W, Yashiro K, Takada K. Orthodontic treatment of malocclusion improves impaired skillfulness of masticatory jaw movements. Angle Orthod 2009;79:1078-1083. doi: 10.2319/052708-282R.1.

17. Yoon W, Hwang S, Chung C, Kim KH. Changes in occlusal function after extraction of premolars: 2-year follow-up. Angle Orthod 2017;87:703-708. doi: 10.2319/112116836.1.

18. Herzog C, Konstantonis D, Konstantoni N, Eliades T. Archwidth changes in extraction vs nonextraction treatments in matched Class I borderline malocclusions. Am J Orthod Dentofacial Orthop 2017;151:735-743. doi: 10.1016/ j.ajodo.2016.10.021.

19. Fueki K, Yoshida E, Igarashi Y. Association between occlusal curvature and food comminution and mixing in human young adults with permanent dentitions. Arch Oral Biol 2013;58:377-383. doi: 10.1016/j.archoralbio.2012.06.006.

20. Ogawa T, Koyano K, Umemoto G. Inclination of the occlusal plane and occlusal guidance as contributing factors in mastication. J Dent 1998;26:641-647.

21. Uesugi H, Shiga H. Relationship between masticatory performance using a gummy jelly and masticatory movement. J Prosthodont Res 2017;61:419-425. doi: 10.1016/ j.jpor.2017.01.001

22. Bourdiol P, Soulier-Peigue D, Lachaze P, Nicolas E, Woda A, Hennequin M. Only severe malocclusion correlates with mastication deficiency. Arch Oral Biol 2017;75:14-20. doi: 10.1016/j.archoralbio.2016.12.002.

23. Komino M, Shiga H. Changes in mandibular movement during chewing of different hardness foods. Odontology 2017;105:418-425. doi: 10.1007/s10266-016-0292-z. 